\title{
NÍVEIS ADEQUADOS E TÓXICOS DE BORO NA PRODUÇÃO DE ARROZ, FEIJÃO, MILHO, SOJA E TRIGO EM SOLO DE CERRADO
}

\author{
Nand Kumar Fageria ${ }^{1}$
}

\begin{abstract}
RESUMO
Foram conduzidos cinco experimentos em casa de vegetação, para determinação de teores adequados e tóxicos de B no solo e nas plantas de arroz, feijão, milho, soja e trigo, cultivados em vasos. Os tratamentos com B consistiram de $0,1,2,3,6,12$ e $24 \mathrm{mg} \mathrm{kg}^{-1}$ de solo aplicado para o arroz e milho, e de $0,1,2,3,6$, e $12 \mathrm{mg} \mathrm{kg}^{-1}$ de solo para o feijão, soja e trigo. A produção máxima de matéria seca da parte aérea de arroz, feijão, milho, soja e trigo, foi obtida com a aplicação de $0,4,2,0,4,7,3,4$ e $0,4 \mathrm{mg} \mathrm{kg}^{-1}$ no solo, respectivamente, enquanto os níveis tóxicos de $\mathrm{B}$ aplicados com base na redução de $10 \%$ na produção, foram de 3, 4,4, 8,7, 6,9 e 7,4 $\mathrm{mg} \mathrm{kg}^{-1}$ de solo, respectivamente, para as mesmas culturas. Conforme a análise do solo, os níveis adequados de $\mathrm{B}$ para o arroz, feijão, milho, soja e trigo foram $0,4,0,9,1,3,2,6$ e $0,4 \mathrm{mg} \mathrm{kg}^{-1}$, respectivamente, mas a toxidez, nas mesmas culturas ocorreu quando a análise de solo mostrou teores de 2,3, 2,8, 5,7, 5,2 e 4,3 $\mathrm{mg} \mathrm{B} \mathrm{kg}^{-1}$. Os níveis adequados na planta variaram de 10 a $75 \mathrm{mg} \mathrm{B} \mathrm{kg}^{-1} \mathrm{e}$ os tóxicos de $20 \mathrm{a} 153 \mathrm{mg} \mathrm{B} \mathrm{kg}^{-1}$, dependendo da cultura.
\end{abstract}

Palavras-chave: produção de matéria seca, comprimento das raízes, teor de B na planta, teor de B no solo

\section{ADEQUATE AND TOXIC LEVELS OF BORON FOR RICE, COMMON BEAN, CORN, SOYBEAN AND WHEAT PRODUCTION IN CERRADO SOIL}

\begin{abstract}
Five greenhouse experiments were conducted to determine adequate and toxic levels of boron in upland rice, common bean, corn, soybean and wheat. The boron treatments were $0,1,2,3,6,12$ and $24 \mathrm{mg} \mathrm{B} \mathrm{kg}^{-1}$ of soil for rice and corn and $0,1,2,3,6$ and $12 \mathrm{mg} \mathrm{B} \mathrm{kg}^{-1}$ of soil for common bean, soybean and wheat crops. Maximum dry matter yield of the tops of rice, common bean, corn, soybean, and wheat was obtained with the application of $0.4,2.0,4.7,3.4$, and $0.4 \mathrm{mg} \mathrm{B} \mathrm{kg}^{-1}$ of soil, respectively. Toxic levels of $\mathrm{B}$, responsible for a $10 \%$ yield reduction were 3.0, 4.4, 8.7, 6.8, and 7.4 $\mathrm{B} \mathrm{kg}{ }^{-1}$, respectively for the same crops and, based on soil analysis, the adequate levels of B were found to be $0.4,0.9,1.3,2.6$ and $0.4 \mathrm{mg} \mathrm{B} \mathrm{kg}^{-1}$ of soil. Similarly, the toxic levels of B in the soil for these crops were $2.3,2.8,5.7,5.2$, and $4.3 \mathrm{mg} \mathrm{B} \mathrm{kg}^{-1}$ of soil, respectively. Adequate levels of B in the plant tissues varied from 10 to $75 \mathrm{mg} \mathrm{B} \mathrm{kg}^{-1}$ and toxic levels varied from 20 to $153 \mathrm{mg} \mathrm{B} \mathrm{kg}^{-1}$ of dry tissue depending on crops.
\end{abstract}

Key words: dry matter yield, root length, B concentration in plant, B concentration in soil 


\section{INTRODUÇÃO}

O boro é um elemento essencial para o desenvolvimento normal das culturas anuais, participando de várias reações biológicas; sua deficiência é relatada em vários tipos de solo, em várias partes do mundo (Sah \& Brown, 1997) além de, em diversas culturas anuais no Brasil, provocar grandes perdas de produtividade (Bataglia \& Raij, 1990). Foram relatadas respostas de aplicação de boro em algumas culturas anuais em solo de cerrado (Galrão, 1984; Buzetti et al., 1990; Carvalho et al., 1996); entretanto, a maioria dos trabalhos tem avaliado o efeito de um conjunto de micronutrientes impossibilitando, portanto, concluir o efeito de cada elemento isolado (Galrão, 1991). Ainda os trabalhos realizados, tanto em casa de vegetação como no campo, somente testaram duas ou três doses de micronutrientes, o que não é suficiente para determinar níveis adequados e tóxicos no solo e na planta; além disso, a importância dos micronutrientes é aumentada com a introdução do sistema de irrigação via pivô central na região central do país, onde são plantadas pelo menos duas safras por ano. A recomendação do uso de boro na adubação, entretanto, não pode ser indiscriminada, uma vez que esse micronutriente pode tornar-se tóxico, se aplicado em excesso, razão pela qual é necessário se conhecer os níveis adequados deste elemento no solo e na planta, para se fazer uma recomendação correta.

O objetivo deste trabalho foi determinar níveis adequados e tóxicos de boro no solo e na planta para as culturas de arroz, feijão, milho, soja e trigo.

\section{MATERIAL E MÉTODOS}

Foram conduzidos cinco experimentos em casa de vegetação, na Embrapa Arroz e Feijão, em Santo Antônio de Goiás, GO, utilizando-se um Latossolo Vermelho-Escuro, textura argilosa. Os resultados das análises química e granulométrica do solo utilizado no ensaio foram: $\mathrm{pH}$ - 4,9 em água (1:2,5), P - 0,9 mg kg-1 $\mathrm{K}-44 \mathrm{mg} \mathrm{kg}^{-1}, \mathrm{Ca}-0,5 \mathrm{cmol} \mathrm{kg}^{-1}$, $\mathrm{Mg}-0,2 \mathrm{cmol}_{\mathrm{c}} \mathrm{kg}^{-1}, \mathrm{Al}-0,7 \mathrm{cmol}_{\mathrm{c}} \mathrm{kg}^{-1}, \mathrm{Cu}-1,3 \mathrm{mg} \mathrm{kg}^{-1}, \mathrm{Zn}-2,1$ $\mathrm{mg} \mathrm{kg}{ }^{-1}, \mathrm{Fe}-82 \mathrm{mg} \mathrm{kg}^{-1}, \mathrm{Mn}-14 \mathrm{mg} \mathrm{kg}^{-1}, \mathrm{~B}-0,4 \mathrm{mg} \mathrm{kg}^{-1} \mathrm{e}$ matéria orgânica - $19 \mathrm{~g} \mathrm{~kg}^{-1}$; a análise textural mostrou $550 \mathrm{~g}$ $\mathrm{kg}^{-1}$ de argila, $130 \mathrm{~g} \mathrm{~kg}^{-1}$ de silte e $320 \mathrm{~g} \mathrm{~kg}^{-1}$ de areia. O P e K foram extraídos pelo extrator Mehlich $1 \mathrm{e}, \mathrm{o} \mathrm{Ca}$, o $\mathrm{Mg}$ e o $\mathrm{Al}$ pelo $\mathrm{KCl} 1 \mathrm{~N}$. Na solução extraída, o $\mathrm{P}$ foi determinado por colorimetria e o $\mathrm{K}$ por fotometria de chama. $\mathrm{O} \mathrm{Ca}$ e o $\mathrm{Mg}$ foram determinados por titulação utilizando-se EDTA e o Al por titulação com $\mathrm{NaOH}$. Os micronutrientes $\mathrm{Cu}, \mathrm{Zn}$, Fe e Mn foram determinados na mesma solução utilizada para $\mathrm{P}$, por absorção atômica, e a matéria orgânica o foi pelo método de Walkley \& Black. O boro foi extraído com água quente e determinado pelo método colorimétrico com azometina-H (Bataglia \& Raij, 1990) e a análise granulométrica foi realizada pelo método da pipeta.

Os tratamentos consistiram de sete doses de B: 0, 1, 2, 3, 6,12 e $24 \mathrm{mg} \mathrm{B} \mathrm{kg}^{-1}$ de solo para o arroz (Oryza sativa L.) e o milho (Zea mays L.) e de 0, 1, 2, 3, 6, e $12 \mathrm{mg} \mathrm{B} \mathrm{kg}^{-1}$ de solo para o feijão (Phaseolus vulgaris L.), soja (Glycine max L. Merr.) e trigo (Triticum aestivum L.), aplicado como ácido bórico $(17,5 \% \mathrm{~B})$. O experimento foi conduzido em vaso plástico com $5 \mathrm{~kg}$ de terra, em que cada vaso recebeu $20 \mathrm{~g}$ de calcário, para aumentar os teores de $\mathrm{Ca}$ e $\mathrm{Mg}$ e o $\mathrm{pH}$. O calcário utilizado na incubação continha 31,4\% de $\mathrm{CaO}, 11,6 \%$ de $\mathrm{MgO}$ e um PRNT igual a 69\% e a incubação ocorreu 29 dias antes do plantio. Na época de plantio, cada vaso recebeu $400 \mathrm{mg}$ de $\mathrm{N}$, como sulfato de amônio, $983 \mathrm{mg}$ de P, como superfosfato triplo, $896 \mathrm{mg}$ de $\mathrm{K}$, como cloreto de potássio e $50 \mathrm{mg}$ de $\mathrm{Zn}$, como sulfato de zinco. O delineamento experimental foi o de blocos inteiramente casualizados, com três repetições e quatro plantas por vaso. O trigo e o milho foram colhidos três semanas após o plantio, a soja e o arroz, quatro semanas após o plantio e o feijão, 25 dias após o plantio. Após a colheita da parte aérea, foram tiradas as raízes e lavadas com água destilada várias vezes e medido o comprimento máximo; o material foi secado e pesado para determinação do peso seco, enquanto a parte aérea, após secagem, foi moída e o B determinado de acordo com o método citado por Correa et al. (1985). Após a colheita das plantas, foram coletadas amostras de solo em cada vaso, separadamente, para determinação de $\mathrm{B}$ e pH. O pH dos tratamentos variou de 5,6 a 6,0, com média geral de 5,8.

Os dados foram submetidos à análise de variância e utilizadas equações de regressão, para se avaliar os efeitos dos tratamentos.

\section{RESULTADOS E DISCUSSÃO}

O peso da matéria seca da parte aérea e das raízes para todas as culturas à exceção do trigo, foi significativamente afetado pelos tratamentos de boro (Tabela 1); entretanto, o comprimento das raízes não foi influenciado significativamente com a aplicação de boro, com exceção do arroz. Para se determinar as dosagens adequadas e tóxicas de boro aplicados ao solo e os teores de boro adequados e tóxicos baseados na análise de solo e planta apresentaram-se, como produção relativa, os dados de produção de matéria seca da parte aérea em função das doses de boro aplicadas no solo ou do teor de boro no solo ou na planta, utilizando-se equações de regressão (Figuras 1, 3 e 4). Esta metodologia é considerada apropriada na determinação de níveis adequados e tóxicos, porque o lucro da adubação geralmente atinge o máximo na faixa de 90 a $95 \%$ de produtividade relativa (Fageria et al., 1997). A dose adequada de B foi calculada com base na equação de regressão quadrática, cujo coeficiente de regressão $b_{1}$ foi positivo. No caso em que a equação de regressão mostrou coeficiente $b_{1}$ negativo, o valor original de B no solo foi considerado conveniente, como se verificou com o arroz e o trigo.

O nível tóxico de B foi calculado com base em $10 \%$ de redução da produção relativa, após atingir o nível máximo e, no caso do arroz, a dose adequada de B foi a $0,4 \mathrm{mg} \mathrm{kg}^{-1}$ e a dose tóxica, $3 \mathrm{mg} \mathrm{kg}^{-1}$ (Figura 1). Na cultura do feijoeiro, a dose oportuna de B foi de $2 \mathrm{mg} \mathrm{kg}^{-1}$ e a tóxica $4,4 \mathrm{mg} \mathrm{kg}^{-1} \mathrm{de}$ B aplicado. No caso do milho, a dose adequada foi $4,7 \mathrm{mg} \mathrm{kg}^{-1} \mathrm{e}$ a tóxica $8,7 \mathrm{mg} \mathrm{kg}^{-1}$ de $\mathrm{B}$ aplicado. A produção máxima de matéria seca da parte aérea de soja foi obtida com a aplicação de 3,4 mg B kg-1 e, 6,8 $\mathrm{mg} \mathrm{B} \mathrm{kg}^{-1}$ foi a dose tóxica para esta cultura, enquanto para o trigo, a dose apropriada foi de 0,4 mg B kg${ }^{-1}$ e a tóxica de 7,4 mg B kg-1 aplicado no solo. Esses 
resultados mostraram que as gramíneas como arroz e trigo são mais eficientes no uso de B, para crescimento, que as leguminosas, como feijão e soja. Gupta et al. (1985) relataram que, em geral, as plantas da família das gramíneas necessitam de menos B que as leguminosas e, quanto ao B, não existem dados experimentais que citem doses adequadas nem tóxicas para as culturas anuais, como arroz, feijão, milho, soja e trigo, em solos de cerrado; entretanto, Galrão (1991) relatou o aumento da produção de soja com aplicação de $1 \mathrm{mg} \mathrm{B} \mathrm{kg}^{-1}$

Tabela 1. Produção de matéria seca da parte aérea e das raízes de cinco culturas, sob diferentes tratamentos de boro

\begin{tabular}{|c|c|c|c|}
\hline \multirow{2}{*}{$\begin{array}{l}\text { Boro Aplicado } \\
\quad\left(\mathrm{mg} \mathrm{kg}^{-1}\right)\end{array}$} & \multicolumn{2}{|c|}{ Produção da Matéria Seca } & \multirow{2}{*}{$\begin{array}{c}\text { Comprimento } \\
\text { das Raízes } \\
(\mathrm{cm})\end{array}$} \\
\hline & \multicolumn{2}{|c|}{$\left(\mathrm{g}\right.$ vaso $\left.^{-1}\right)$} & \\
\hline \multicolumn{4}{|c|}{ Arroz } \\
\hline 0 & 1,36 & 0,28 & 32 \\
\hline 1 & 1,44 & 0,32 & 39 \\
\hline 2 & 1,36 & 0,23 & 33 \\
\hline 3 & 1,34 & 0,22 & 31 \\
\hline 6 & 0,95 & 0,19 & 31 \\
\hline 12 & 0,88 & 0,15 & 29 \\
\hline 24 & 0,57 & 0,19 & 22 \\
\hline Teste $\mathrm{F}$ & $* *$ & $* *$ & $* *$ \\
\hline C.V. \% & 10 & 16 & 12 \\
\hline \multicolumn{4}{|c|}{ Feijão } \\
\hline 0 & 5,25 & 1,20 & 51 \\
\hline 1 & 5,03 & 1,47 & 61 \\
\hline 2 & 5,70 & 1,40 & 53 \\
\hline 3 & 5,53 & 1,30 & 51 \\
\hline 6 & 4,57 & 1,10 & 51 \\
\hline 12 & 2,43 & 0,50 & 38 \\
\hline Teste F & $* *$ & $* *$ & $\mathrm{~ns}$ \\
\hline C.V. $\%$ & 10 & 12 & 14 \\
\hline \multicolumn{4}{|c|}{ Milho } \\
\hline 0 & 2,60 & 1,87 & 68 \\
\hline 1 & 2,63 & 2,27 & 58 \\
\hline 2 & 3,13 & 1,73 & 61 \\
\hline 3 & 3,23 & 1,77 & 66 \\
\hline 6 & 2,60 & 1,40 & 72 \\
\hline 12 & 2,67 & 1,20 & 55 \\
\hline 24 & 2,10 & 0,90 & 55 \\
\hline Teste F & $* *$ & $* *$ & $\mathrm{~ns}$ \\
\hline C.V. $\%$ & 10 & 20 & 14 \\
\hline \multicolumn{4}{|c|}{ Soja } \\
\hline 0 & 2,23 & 0,67 & 63 \\
\hline 1 & 2,43 & 0,90 & 62 \\
\hline 2 & 2,57 & 0,77 & 60 \\
\hline 3 & 2,37 & 0,67 & 55 \\
\hline 6 & 2,37 & 0,63 & 55 \\
\hline 12 & 1,63 & 0,33 & 46 \\
\hline Teste F & $* *$ & $* *$ & ns \\
\hline C.V. \% & 10 & 18 & 19 \\
\hline \multicolumn{4}{|c|}{ Trigo } \\
\hline 0 & 0,39 & 0,28 & 51 \\
\hline 1 & 0,38 & 0,29 & 44 \\
\hline 2 & 0,39 & 0,29 & 47 \\
\hline 3 & 0,37 & 0,27 & 52 \\
\hline 6 & 0,36 & 0,29 & 48 \\
\hline 12 & 0,31 & 0,22 & 43 \\
\hline Teste F & $\mathrm{ns}$ & ns & ns \\
\hline C.V. \% & 12 & 11 & 9 \\
\hline
\end{tabular}

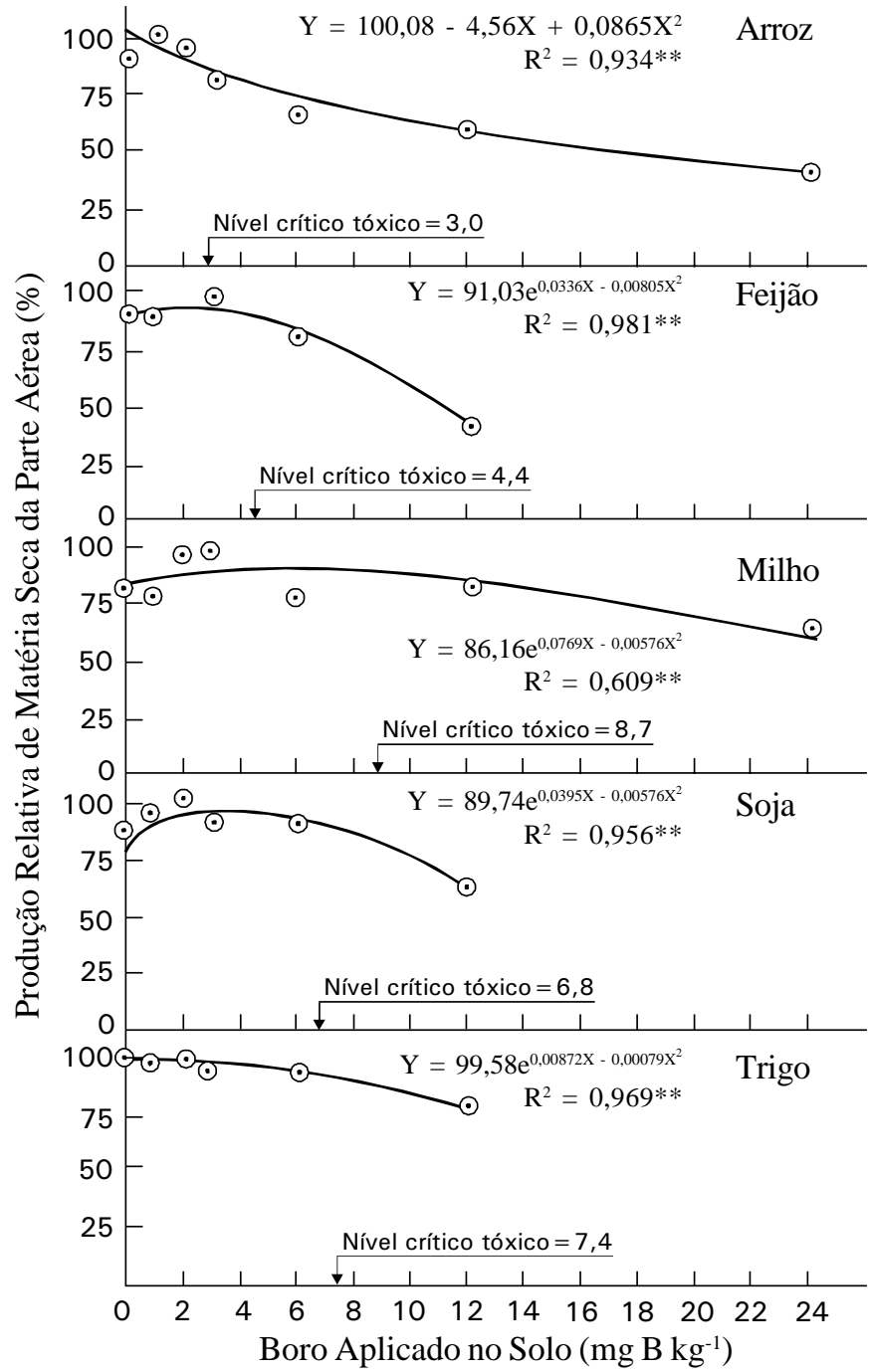

Figura 1. Relação entre boro aplicado no solo e produção relativa da matéria seca da parte aérea de arroz, feijão, milho, soja e trigo

do solo, em comparação com a testemunha. Fageria et al. (1997) afirmaram que a deficiência de B na maioria dos solos pode ser corrigida com a aplicação de 1 a $3 \mathrm{~kg}$ de $\mathrm{B} \mathrm{ha}^{-1}$ para as culturas anuais. Gupta et al. (1985) relataram que a dose de B para o arroz e o trigo, extraído com água quente, está na faixa de 0,1 a $0,5 \mathrm{mg} \mathrm{kg}^{-1}$.

As raízes das plantas são importantes parâmetros de crescimento, devido à sua importância na absorção de nutrientes e água e possuem alta correlação com a produção de matéria seca (Figura 2). Foram determinadas as doses adequadas de $\mathrm{B}$ na produção de matéria seca das raízes (Tabela 2), cujos valores variaram de 0,4 a 2,9 mg B kg-1 do solo, dependendo das culturas. A sensibilidade do sistema radicular em relação ao B está na ordem de trigo $>$ feijão > soja > arroz > milho, significando que a cultura de trigo necessita mais de B para o desenvolvimento do sistema radicular e que o arroz e o milho precisam de um mínimo de $\mathrm{B}$ para o crescimento do sistema radicular.

A análise de solo é um dos principais parâmetros de avaliação da sua fertilidade, razão por que foram calculados os teores de $\mathrm{B}$ adequado e tóxico no solo em relação à produção relativa da parte aérea (Figura 3 ). O teor de B 


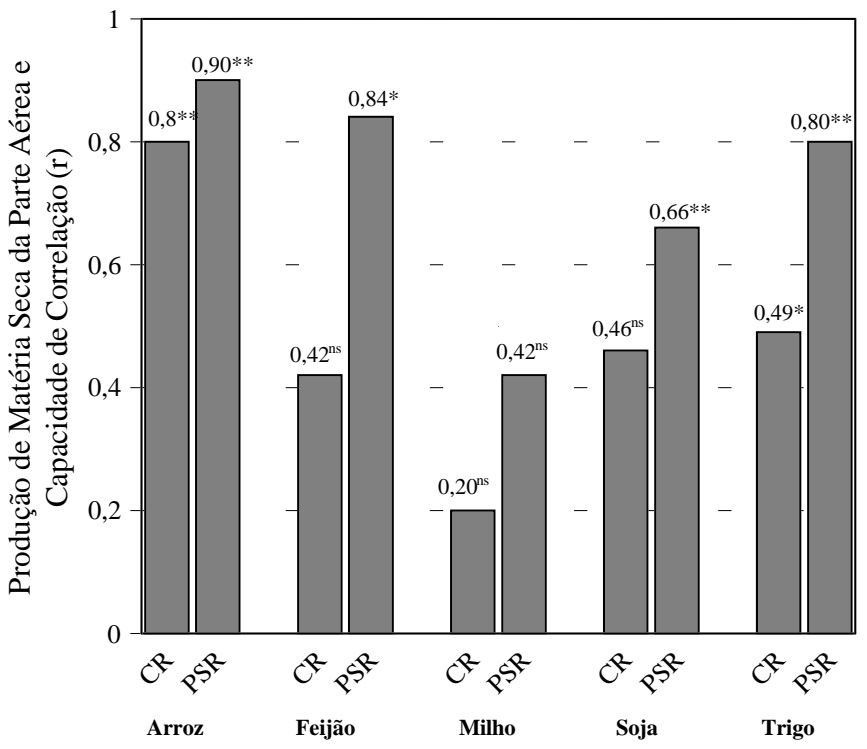

$\mathrm{CR}=$ Comprimento da raiz, $\mathrm{PSR}=$ Peso seco da raiz

Figura 2. Correlação entre a produção de matéria seca da parte aérea, comprimento e peso seco das raízes (ns, *, ** - não significante, significante a 0,05 e 0,01 nível de probabilidade

Tabela 2. Relação entre produção relativa de matéria seca das raízes (y) e dose de boro aplicado no solo (x)

\begin{tabular}{|c|c|c|c|}
\hline Cultura & Equação de Regressão & $\mathrm{R}^{2}$ & $\begin{array}{c}\text { Valor Adequado } \\
\left(\mathrm{mg} \mathrm{kg}^{1}\right)\end{array}$ \\
\hline Arroz & $y=98,09 e^{-0,1035 x+0,00198 x^{2}}$ & $0,951 * *$ & 0,4 \\
\hline Feijão & $y=88,32 e^{0,0365 x-0,00972 x^{2}}$ & $0,975 * *$ & 1,9 \\
\hline Milho & $y=90,03 \mathrm{e}^{-0,0587 \mathrm{x}+0,00104 \mathrm{x}^{2}}$ & $0,924 *$ & 0,4 \\
\hline Soja & $y=83,41 e^{0,0109 x-0,00658 x^{2}}$ & $0,904 *$ & 0,8 \\
\hline Trigo & $y=96,59 e^{0,01858 x-0,00317 x^{2}}$ & $0,894 *$ & 2,9 \\
\hline
\end{tabular}

adequado no solo foi de $0,4 \mathrm{mg} \mathrm{B} \mathrm{kg}^{-1}$ para o arroz, de 0,9 mg B kg-1 para a cultura de feijão, de $1,3 \mathrm{mg} \mathrm{B} \mathrm{kg}^{-1}$ para o milho, de 2,6 mg B kg-1 para a soja e de $0,4 \mathrm{mg} \mathrm{B} \mathrm{kg}^{-1}$ para o trigo, enquanto o nível tóxico foi de $2,3 \mathrm{mg} \mathrm{B} \mathrm{kg}^{-1}$ para o arroz, de 2,8 mg B kg-1 para o feijão, de $5,7 \mathrm{mg} \mathrm{B} \mathrm{kg}^{-1}$ para o milho, de 5,2 $\mathrm{mg} \mathrm{B} \mathrm{kg}^{-1}$ para a soja e de $4,3 \mathrm{mg} \mathrm{B} \mathrm{kg}^{-1}$ para o trigo. Cox (1987) relatou níveis suficientes de B no solo entre 0,1 a $2 \mathrm{mg} \mathrm{B} \mathrm{kg}^{-1}$, dependendo das culturas, sendo que os valores obtidos para todas as culturas estão nesta faixa, porém uma pequena diferença deve estar relacionada com o pH do solo. De acordo com Su et al. (1994) a adsorção de $\mathrm{B}$ em solos ácidos aumenta com a aplicação de $\mathrm{CaCO}_{3}$, assim com os níveis adequados e tóxicos; o nível tóxico de B no solo para a cultura de feijão é relatado como maior que $2 \mathrm{mg} \mathrm{B} \mathrm{kg}^{-1}$ (Robertson et al., 1975). Gupta (1983) também relatou valor de $4 \mathrm{mg} \mathrm{B} \mathrm{kg}^{-1}$ do solo como nível tóxico para as culturas de feijão e milho.

Os níveis adequados de $\mathrm{B}$ na parte aérea obedeceram a seguinte ordem: soja > feijão > milho > trigo > arroz (Figura 4) significando que a soja acumulou mais $B$ que as outras culturas. Os níveis tóxicos foram da ordem de soja $>$ trigo $>$ feijão > milho > arroz e o nível adequado de B na parte aérea do arroz é relatado como $20 \mathrm{mg} \mathrm{B} \mathrm{kg}^{-1}$, feijão $10-50$ mg B kg ${ }^{-1}$, milho 7-25 mg B kg-1, soja 21-55 $\mathrm{mg} \mathrm{B} \mathrm{kg}^{-1}$ e trigo 6-10 $\mathrm{mg} \mathrm{B} \mathrm{kg}^{-1}$ na fase inicial de crescimento das culturas

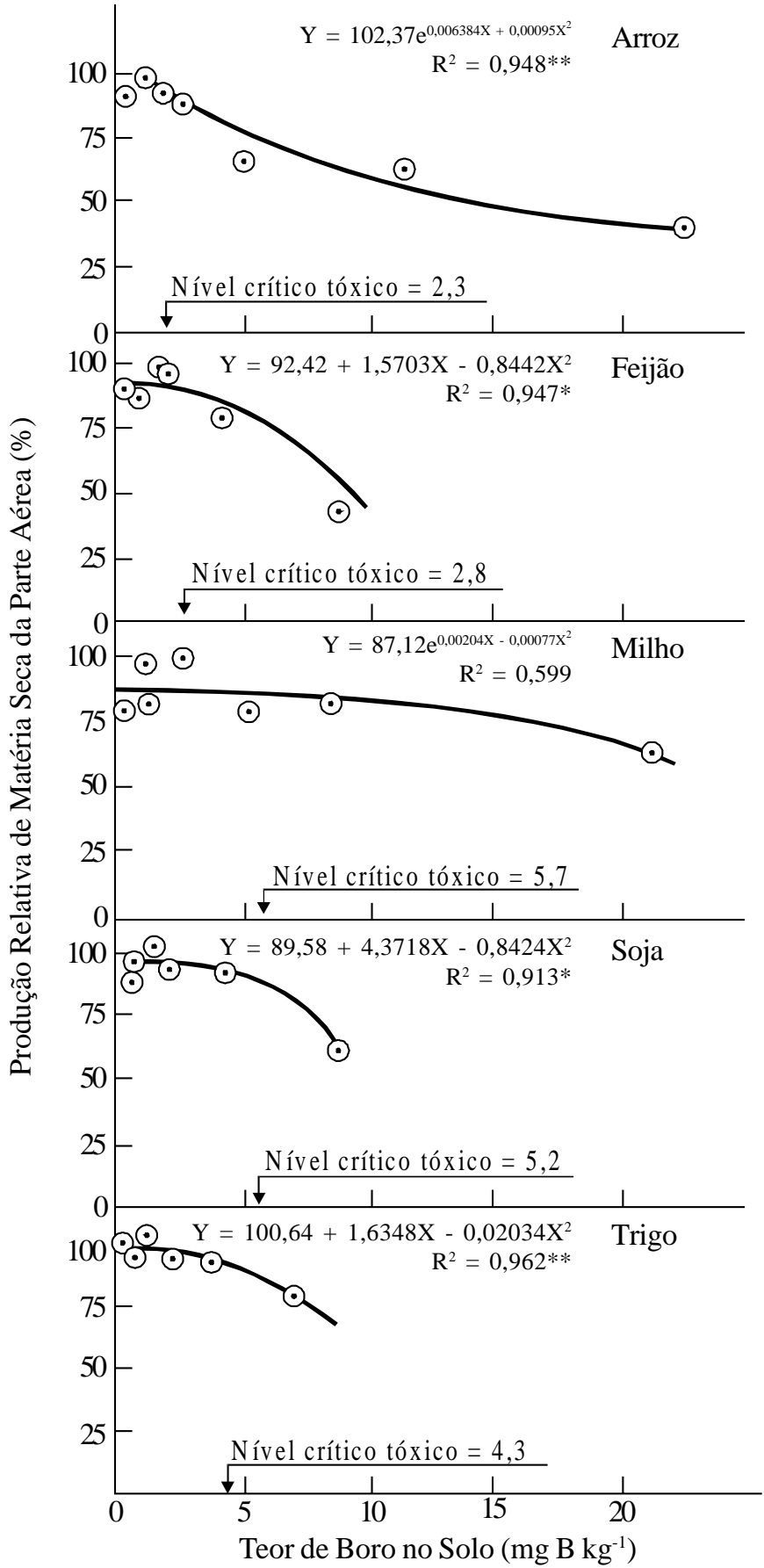

Figura 3. Relação entre teor de boro no solo e produção relativa da matéria seca da parte aérea de arroz, feijão, milho, soja e trigo

(Fageria et al., 1997) Os resultados estão mais ou menos na mesma faixa de concentração e não existem dados de toxidez de micronutrientes na planta para se fazer comparação.

A acumulação de B em função do boro aplicado está apresentada na Figura 5 e foi altamente significativa e quadrática em todas as culturas; já a acumulação máxima foi para feijão, seguido pelo milho e soja, e a mínima correspondeu ao trigo, seguido pela cultura de arroz. Esta diferença na acumulação está relacionada com a produção de matéria seca da parte aérea e, também, com a diferente capacidade de cada espécie na absorção e acumulação. 


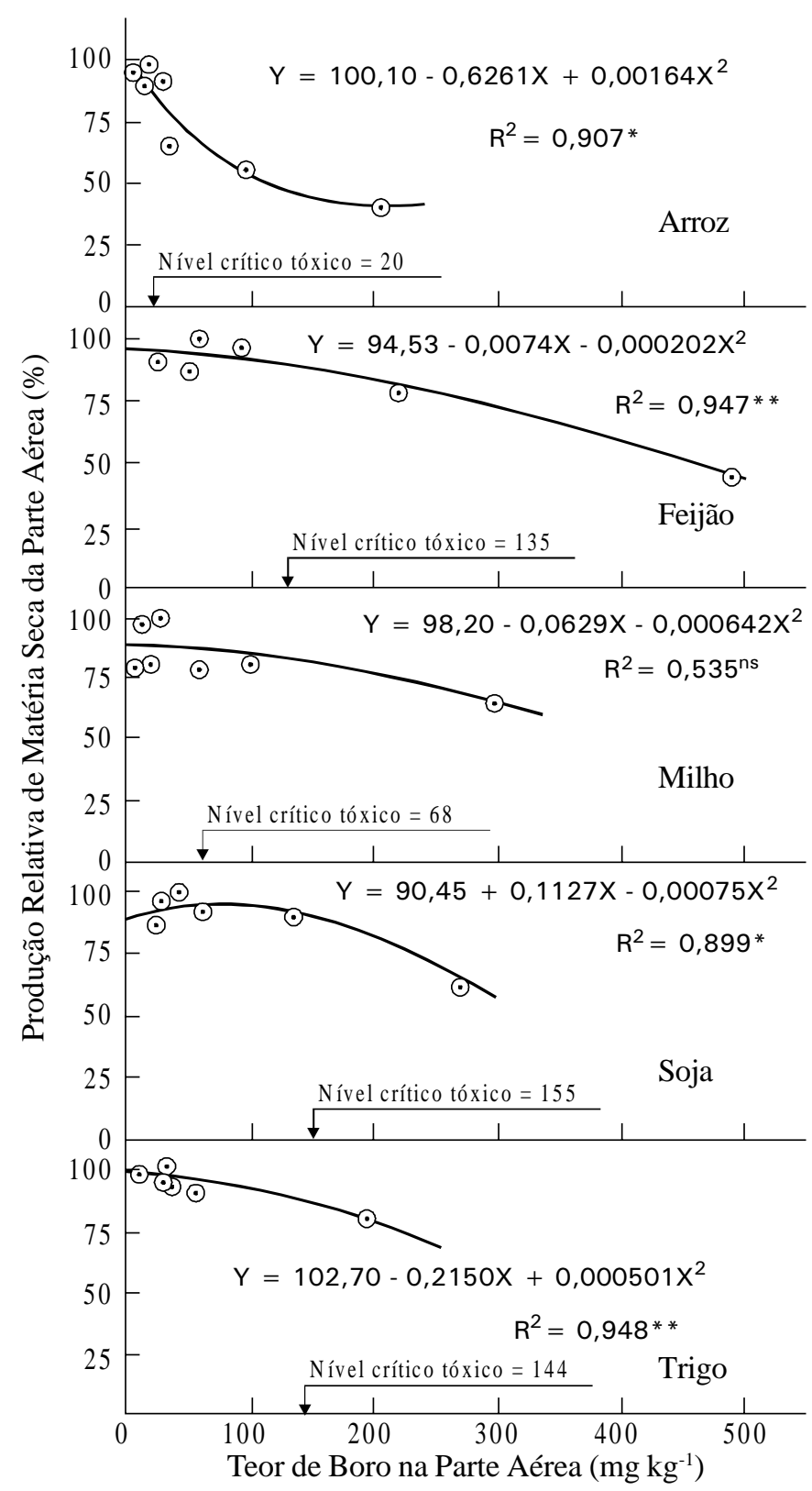

Figura 4. Relação entre teor de boro na parte aérea da planta e produção relativa de matéria seca da parte aérea de arroz, feijão, milho, soja e trigo

\section{CONCLUSÕES}

1. O boro influenciou a produção de matéria seca da parte aérea e de raízes e o comprimento das raízes de arroz, feijão, milho, soja e trigo, mas a resposta variou conforme a cultura.

2. As dosagens de boro que propiciaram a máxima produção de matéria seca da parte aérea variaram entre 0,4 e $4,7 \mathrm{mg} \mathrm{B} \mathrm{kg}^{-1}$ de solo aplicado para as culturas de arroz, feijão, milho, soja e trigo e as doses tóxicas variaram de 3 a $8,7 \mathrm{mg} \mathrm{B} \mathrm{kg}^{-1}$ de solo aplicado, para as mesmas culturas.

3. A necessidade das culturas em relação ao boro aplicado foi na ordem arroz $<$ trigo $<$ feijão $<$ soja $<$ milho.

4. A acumulação de boro nas cinco culturas avaliadas aumenta quadraticamente com a aplicação do elemento no solo.

5. Os níveis tóxicos de $\mathrm{B}$ na parte aérea estão entre 20 a 153 $\mathrm{mg} \mathrm{B} \mathrm{kg}{ }^{-1}$, para as cinco culturas avaliadas.

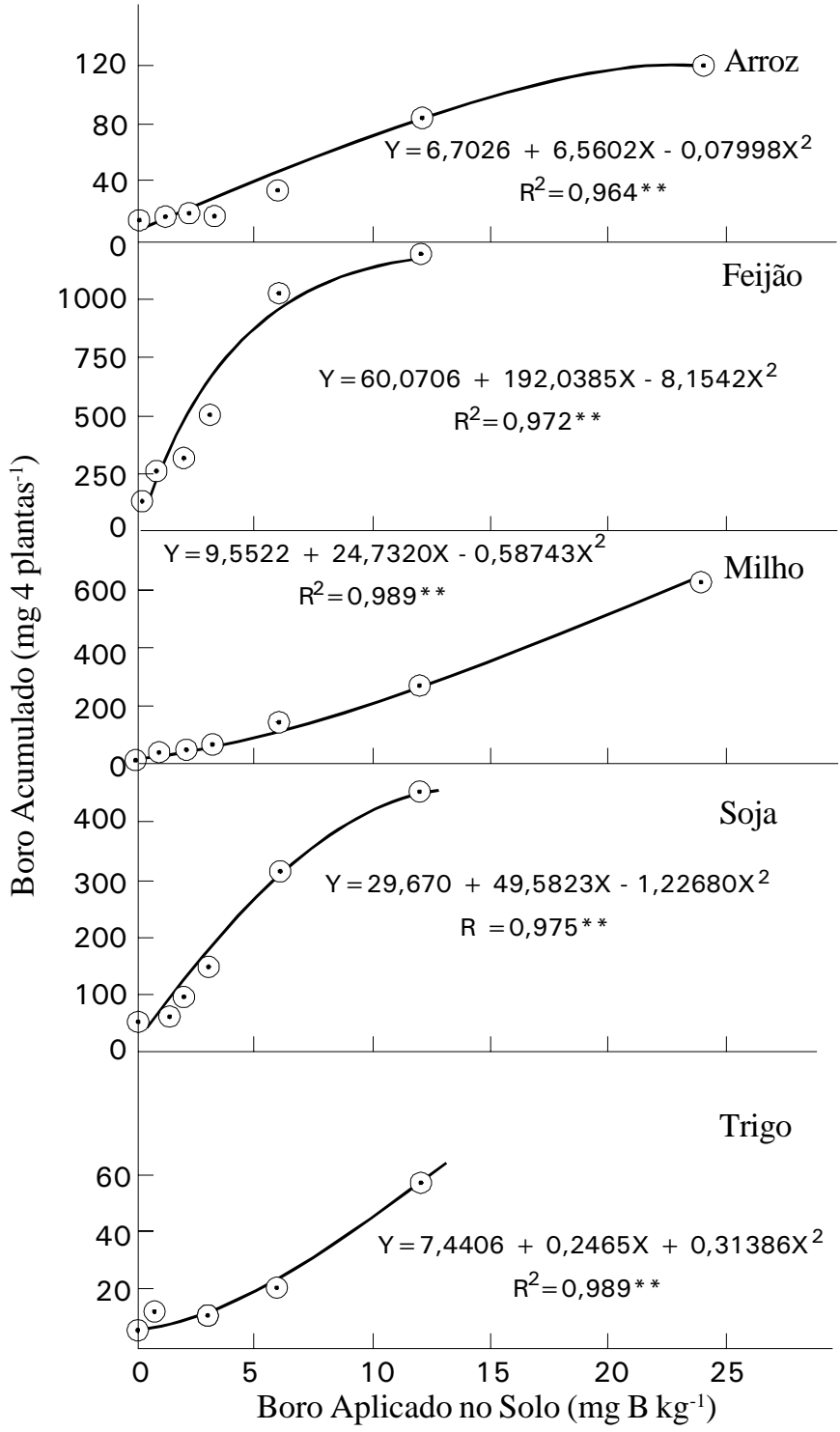

Figura 5. Relação entre boro aplicado no solo e acumulação de boro na parte aérea de arroz, feijão, milho, soja e trigo

\section{REFERÊNCIAS BIBLIOGRÁFICAS}

BATAGLIA, O.C.; RAIJ, B. van. Eficiência de extratores na determinação de boro em solos. Revista Brasileira de Ciência do Solo, Campinas, v.14, n.1, p.25-31, 1990.

BUZETTI, S.; MURAOKA, T.; SÁ, M.E. de. Doses de boro na soja, em diferentes condições de acidez do solo. I. Produção de matéria seca e de grãos e nível crítico no solo. Revista Brasileira de Ciência do Solo, Campinas, v.14, n.2, p.157-161, 1990.

CARVALHO, L.H.; SILVA, N.M.; BRASIL SOBRINHO, M.O.C.; KONDO, J.I.; CHIAVEGATO, E.J. Aplicação de boro no algodoeiro, em cobertura e em pulverização foliar. Revista Brasileira de Ciência do Solo, Campinas, v.20, n.2, p.265-269, 1996.

CORREA, A.E.; MIYAZAWA, M.; PAVAN, M.A. Método de não-digestão para extração de boro em folhas de plantas. Pesquisa Agropecuária Brasileira, Brasília, v.20, n.10, p.12131216, 1985. 
COX, F.R. Micronutrient soil tests: Correlation and calibration. In: BROWN, J.R. (ed.). Soil testing: Sampling, correlation, and calibration and interpretation. Madison: Soil Science Society of America, 1987. p.97-117.

FAGERIA, N.K.; BALIGAR, V.C.; JONES, C.A. Growth and mineral nutrition of field crops. 2. ed. rev. New York: Marcel Dekker, 1997.656p.

GALRÃO, E.Z. Efeito de micronutrientes e do cobalto na produção e composição química do arroz, milho e soja em solo de cerrado. Revista Brasileira de Ciência do Solo, Campinas, v.8, n.1, p.111-116, 1984.

GALR ÃO, E.Z. Micronutrientes e cobalto no rendimento da soja em solo de cerrado. Revista Brasileira de Ciência do Solo, Campinas, v.15, n.1, p.117-120, 1991.

GUPTA, U.C. Boron deficiency and toxicity symptoms for several crops as related to tissue boron level. Journal of Plant Nutrition, New York, v.6, n.5, p.387-395, 1983.
GUPTA, U.C.; JAME, Y.W.; CAMPBELL, C.A.; LEYSHON, A.J.; NICHOLAICHUK, W. Boron toxicity and deficiency: A review. Canadian Journal of Soil Science, Ottawa, v.65, n.3, p.381-409, 1985.

ROBERTSON, L.S.; KNEZEK, B.D.; BELO, J. A survey of Michigan soils as related to possible boron toxicities. Communications in Soil Science and Plant Analysis, New York, v.6, n.3, p.359-373, 1975.

SAH, R.N.; BROWN, P.H. Techniques for boron determination and their application to the analysis of plant and soil samples. Plant and Soil, Dordrecht, v.193, n.1-2, p.15-33, 1997.

SU, C.; EVANS, L.J.; BATES, T.E.; SPIERS, G.A. Extractable soil boron and alfalfa uptake: Calcium carbonate effects on acid soil. Soil Science Society of America Journal, Madison, v.58, n.5, p.1445-1450, 1994. 